\title{
Interactive comment on "The heavy precipitation event of 14-15 October 2018 in the Aude catchment: A meteorological study based on operational numerical weather prediction systems and standard and personal observations" by Olivier Caumont et al.
}

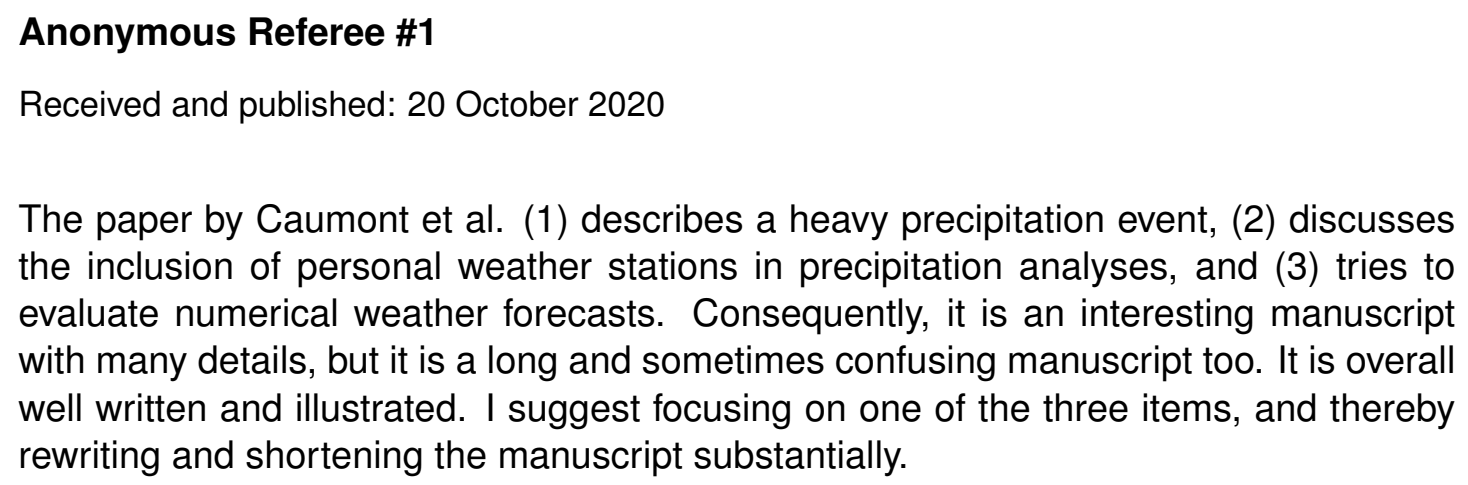

The paper by Caumont et al. (1) describes a heavy precipitation event, (2) discusses the inclusion of personal weather stations in precipitation analyses, and (3) tries to evaluate numerical weather forecasts. Consequently, it is an interesting manuscript with many details, but it is a long and sometimes confusing manuscript too. It is overall well written and illustrated. I suggest focusing on one of the three items, and thereby rewriting and shortening the manuscript substantially.

Printer-friendly version

Discussion paper 
Suppose the focus shall be on event description (1). In that case, I think it will be worth trying to quantify the impact of the mentioned leftovers of a former hurricane, which made the "classic synoptic situation" (line 4) special. These hurricane leftovers were mentioned already in the Abstract, and the reader is hoping for a more in-depth consideration. But, the authors only wrote vaguely in the Conclusion "did not reveal any particular role" and mention that trajectory studies would have been necessary (line 450). They mention (line 452) strong evaporation over the Western Mediterranean Sea, which "most likely contributed to the supply of moisture". It would be interesting to learn if strong winds related to the hurricane leftovers lead to the strong evaporation. The ARPEGE and AROME analysis could help in the discussion of the event processes, but the distraction of discussing the skill of the AROME now- and forecasts should be skipped. Finally, it would be important to discuss the features of this "classic" event in the context of other classic events in the area and beyond in the Mediterranean basin (not France only).

The discussion (2) about the impact of personal weather stations could be kept very short and moved to an Appendix. The discussion of the added value of personal weather stations in the QPE should not be mixed with the event description in Sec. 3.2 .

If evaluation (3) of the AROME now- and forecasts shall be the manuscript's goal, this has to be more conclusive. For example, the authors wrote in the Abstract that the rainfall forecasts had limited predictability (line 9). Which forecast? The forecasts of ARPEGE, AROME-FRANCE, AROME-NWC, or all of the AROME-EPS members? In the Abstract and Conclusion, it is mentioned that the best forecast (one of the EPS members) contained the warmest, wettest, and fastest low-level jet. The EPS is introduced in one sentence only (lines 87-88!) without hinting at the applied perturbation method. Was the one good forecast member just luck? Has the EPS any predictive value for events like the discussed one? Why did the other members miss the important mesoscale features?

Printer-friendly version

Discussion paper 
The discussion of river network, runoff, infiltration, etc. (e.g., page 13) could be skipped or very briefly done in the introduction. The comments on soil moisture (e.g., line 8 ) and NHESSD its role in flood formation (line 458) are misleading as the authors neither discuss any precipitation - soil moisture feedback/recycling, nor discuss the flood event in depth.

Interactive comment on Nat. Hazards Earth Syst. Sci. Discuss., https://doi.org/10.5194/nhess-

Interactive 2020-310, 2020.

comment

Printer-friendly version

Discussion paper 